\title{
Poetic Dwelling
}

\section{The Functional Analysis of the Architectural Ceramics Skin}

\author{
Junxi Zhu \\ Jingdezhen Ceramic Institute \\ Jingdezhen, China 333403
}

\begin{abstract}
This article draws attention to the function of architectural ceramics skin. In the perspective of Heidegger' existentialism and Norberg Schulz' phenomenology of architecture, discuss the three levels of function in architectural ceramics skin: practical function, aesthetic function and culture function, as well as the relationship between them. It revealed the mission of architectural ceramics skin is not only protect the architectural structure from practical function, but also it is a reproduction of poetic aesthetic realm and cultural site. The deep function of architectural ceramics skin is the construction of poetical living place.
\end{abstract}

Keywords—architectural ceramics; skin; function; poetry; sit

\section{INTRODUCTION}

Architectural ceramics skin means: a presenting skin form which inside and outside the building, the ceramic tiles according to a certain arrangement, use paving, mosaics, dry hanging and other combination forms to surround protect the roof and wall surface of the building, so to separate the inside and outside space, control external climate influence, eliminate the destroy from outside force and beatify the architectural space. It includes the tile system grouted on the roof and brick system affixed on the inside and outside wall. From material it can be divided into coarse ceramics, fine ceramics, half porcelain, unglazed tiles, glazed tiles; ceramics brick system can be divided into: ceramic surface brick, colored porcelain grain, ceramics mosaic, building ceramics plate, ceramics brick; and ceramics tile system can be divided into: ball clay tile, glass-pot clay tile, glass tile, ceramics tile. From the entire body of the building it is divided into two parts: body and performance, earthwork foundation and roof frame belong to the former part, while filling the walls and the skin belong to the latter part. The skin construction in the architectural performance level is a practical art that requires both practical and aesthetic. In Vitruvius' "Ten Books of Architecture "it proposed, building as a practical art it has suitable, sturdy and beautiful three attributes. The construction activity essentially is to create a living space, this construction not only meet the basic living condition, but also it is the pursuit of poetic living space. Architectural ceramics skin need to auxiliary build a practical space and protect the solid wall from external damage, but also need to break the limitations of utilitarian thinking, through art creation to make the construction activities tend to create aesthetic space and cultural space.

"Poetic Dwelling" was first proposed by the German philosopher Martin Heidegger." People living poetically." The phrase came from a poem of Holderlin in his later years, Heidegger used it as the theme of a chapter of "poetry, language, thinking" to elucidate the theoretical construction of author's ideal world. People usually regard dwelling as the labor activity, and regard poetic as the characteristic of art. Heidegger believed: Poetry is the dwelling's own characteristic, the fundamental condition of living is so called dwelling. [1] In the text Heidegger constructed the ideal poetic living state in his mind through the Criticism and Reflection of "non-poetic dwelling". He thought that the infinite fascination of material desires of non-poetic dwelling departure from the nature of dwelling, with the aid of tool characteristic of technology to recklessly transform and destroy the nature, destroyed the harmonious way of heaven, earth, man and god quaternity. Scientific thinking is instead of pure thought, thus far from the divinity and humanity. Poetic dwelling precisely change this irrational development mode and cognitive style, as Heidegger said: "What does a Poet do? Poet makes people achieve a poetic existence." [2] The poet use poetry language called for fix over logical thinking which after transformation and over utilitarian-oriented mind. Guard the nature of each object, prevent injury, pursuit of peaceful and free survival philosophy. Achieve the quaternary unity of heaven, earth, human and god.

Architectural ceramics skin art is an artistic creation based on satisfying the basic utility functions. It includes brick wall art, Vatan art, ridge animal art and so on. Art essentially is poetic, artisans and artists through the poetic construction of art to create the territory of aesthetics and human relations which above the daily life.

\section{THE PRACTICAL FUNCTION OF ARCHITECTURAL CERAMICS SKIN-AS THE STRUCTURE GUARDIAN}

Human needs can be divided into physical and spiritual needs. The former includes food, clothing, housing, transportation and other basic needs, which point to human's physical and material activities. The latter with beauty discovery as its core to point the human's psychological and spiritual activities. [3] The construction of residential buildings is the production of human's important subsistence. Construction activities provide the basic material need: satisfied people's need for ideal rest and privacy space, which is practical space construction. So to provide places for people to live. Ceramic materials involved in building skin has a long history, in the thousands of years production life it has always played a normal but important role - shelter from bad weather, maintain the structural robustness. Our brick firing history is 
over two thousand years, brick raw materials are from the earth, the ancients from cave dwelling, nest dwelling developed to ground build dwelling, through fire cooking in the mud house they found that after the ground and walls verification, they will form a hard material with certain strength and waterproof, so they started to specialized firing tiles to reinforcement walls and roof. The bricks and tiles of architectural ceramics skin are the integral part of the stone and wood building, they are the production of farming settled civilization. Also are the tools for agrarian civilization people to defend the alien invasion and build their suitable dwellings.

In "Tiangong Kaiwu" it mentioned: "Building with beams on the top to avoid wind and rain, on the roof covered with tiles." "Prince set up risk battlements and walls to defend its country, so that enemy cannot come" [4]. In ancient, architectural ceramics skin emerged as bricks and tiles which shelter from bad weather and walls built by enemy defenses, its construction motive is defense and shield, which provides survival container for isolation and away from harm and attack. The space within the container means suitable temperature, familiar, free and safe environment to distinguish the storm damage, unacceptable temperature, strange and dangerous environment outside the container.

Ceramic materials have good function value. Ceramics has features of hard texture, corrosion resistant, abrasion resistant, rain-proof, frost resistant, never fade and others, so it has always been the ideal material for architectural skin in the history. Its sturdy carcass is the body for thousand years made by the soil through fire and water forge, its material is very convenient to obtain in the mud booth hillside. After cover the glaze on the surface, then fired at high temperature, it will form with a solid body with certain mechanical strength and corrosion resistance, so in the long history of architecture, it has always appeared as the armor and coat of building. The brick and tile first appeared at the end of slave society, brick is also known as Pi or Ling Di, first appeared in the Warring States Period. In ancient times it mainly used for flooring, walls, large fortifications, masonry walls and the tomb walls. Tile, also known as Meng, it was produced as early as the Western Zhou period, mainly for roof coverings to protect the eave from sun-scorched and rain-drenched.[5] The development of tile and bricks based on the development of human technology and improvement of living requirements continually evolved into a better functional system.

In ancient China, tile is the perfect interpretation for appearance based on functional considerations. Tile system is a complex roof structure system, it is attached to the roof purlins structure, tiles have a wide variety of types and with features to avoid wind and rain attack [6] in the snowy north, they will use five, six or more layers of tiles in order to mitigate the impact of the upper rain falling, they will place drip tiles at eaves. Drip tile is a round pointed low-hanging tile, in the era of wooden frame architectures, it played a role of water proof for wooden architectures. From the motive of this tile act, which is the act to cover the roof with solid product, this is a practical creation act with a highly purposiveness. [7] The ancient roof use recessed area formed between flat tiles and round tiles to divert rain water and use a round pointed tile to make the rain pouring rain outside the area. Today's stack tiles and integrated tile use a double ditches design, which could make a very good effect of water drainage. Also with simple shape and easy to assemble, the weight of stack tile is much lighter than the round tile, it is in fact a good example of practical design. For example, in the double pitch roof and gable and hip roof buildings, rafter will long outstanding under the eaves in order to avoid rafter suffer from annual corrosion attack. People put the convex surface of flat tile and eaves flat tile upward, buckle down on rafter and nailed tight. Another example is the born of glazed tile is also the product of people's functional optimization toward building components based on technology conditions. After the low-temperature firing glazed tile is normal tile after finished and got glaze and firing with low temperature. Its surface is glass glaze made of quartz, feldspar and mineral colorant which can make very good effect on wind proof and water drainage. [8]

From a practical point of view to look the creation activity of ceramics skin, it is the technology construction and tool strengthening for human living environment. Tiles built up the roof system of living entity, through strengthen the shield function to avoid wind and rain attack the roof area in order to offer a strong container body for the living entity. From the combination of flat tile and round tile, to the integrated tile and also from the tile to the glazed tile all reflect the optimized revolution of building shield function and reasonable structure. With the daily life building components production, their usefulness and applicability are the nature of justice. Daily life appliance takes use as the foundation, its production processes are designed for use. Living is for the continuation of life, architectural ceramics based on improvements of durability and robustness, it is the function concentration.

Practical function of brick mainly the surrounding function to the inside and outside wall of the building, from the overall structure of the wall, ceramic brick is the decorative layer at the outermost layer of the wall which protect the basic internal walls, insulation layer and anti crack protective layer, except the basic function to strengthen the sturdiness of architecture body, architectural ceramics skin could also improve the pollution resistibility of architectures. With the improvement of production technology and people's living standard, modern ceramic bricks in addition to durability, also require acidresistant, alkali-resistant, fire-resistant, wear-resistant, strong resistance, low water absorption, non-porous, easy to clean, and many other advantages. Outer wall bricks used for exterior of the building has to be durable, non-fading, frost resistant, corrosion resistant and self-washing by rain. Ceramic bricks appeared not only as a high-grade exterior building decorative material, but also extend into the interior decoration of the building space, it needs to play many different functional roles in upscale restaurants, public bathhouse, toilets, workshops, laboratories and other different places. Famous ceramic artist Professor Zhu Legeng's design for music ceramic reflector wall of Korea Wheat music hall is the use of ceramic brick in music hall environment. The Subtle arc tile design and ceramics material's own good sound transmission make the sound effect of wheat music hall beyond the ordinary plywood, wood and fiberglass. 


\section{AESTHETIC FUnCTION OF ARCHITECTURAL CERAMICS SKIN-AS A POETIC WEAVER}

Since the moment that living conditions have been satisfied, the purpose of construction activities have been transferred from the utility level to create a practical space into the spiritual enjoyment level of aesthetic. As "Mozi. Yiwen" mentioned: "Home must be very safe, and then pursuit enjoyment". Li Zehou considered aesthetics is the software of "naturalization of person", naturalization of people makes people's spiritual needs return to nature. People struggled to free themselves from the practical world where they work so hard for living, they feel the poetic living from aesthetic activities and enjoy the living freedom. So that to expand human potential and talent. [9] Heidegger quoted Holderlin's verse in his poem "poetry, language, thinking": "full of merit, but people living poetically on this earth." He believed that human living are the existing state on the earth and under the sky. The construction of buildings and the production of tools belong to merit, we cannot rely on them to achieve poetic dwelling, only to rely on poet's speech and calling to measure the divinity scale, so that to achieve poetic dwelling. The poetry art that Heidegger expected actually also implied those art forms which not belong to poetry but within the same artistic field. Architectural Ceramics Skin Art is such a visual art form. They are the crystallization of merit, for thousands of years has been faithfully guarded the buildings, but they are also the poetry which create dreamland, and inspire us to ponder the existence of human from a more nature level. Poetry replies on language to constitute image, create illusion, and ceramic tiles which make up the building skin rely on visual language, create a mood with the material and the form.

The beauty of architectural ceramics skin is the true beauty of simple and elegant carcass, the luxury beauty of shiny glaze and the abstract order beauty caused by paving layer by layer.

The simple elegance of the true beauty of the ceramic tiles mainly presented as the exhibition of construction ceramic tiles to the natural beauty, behind which it reflects the internal relationship between the whole life processes from generates until digestion and the nature earth. Architectural ceramics skin chooses the most natural-related material - clay, this material is taken directly from the earth, it is the most natural material which human beings understand and use. It looks rough with loose structure. Visual, tactile, and even intellectual all face a non-stereotypical object and a wild original state. "The Bible" said, at the beginning of the world, the earth has "no definite shape and is exposed". [10] The presented appearance of bricks and tiles are similar. The production of bricks and tiles are the process for clay's curing amorphous, craftsmen did not change the texture which belongs to earth and the bare body. On a deeper level, the bricks and tiles only generate but do not stop the inherent kinship with the earth. Clay just goes from non-amorphous to amorphous transition. Its production, use and demise never left the earth. Potters exhibit the natural beauty of this material to the world through the architecture works which attached with. Architectural ceramics skin (brick) production process is full of handmade merits: bulge caused by fingers kneading, lines caused by trowel crossing. These handmade marks show beauty on bricks and tiles which is the inherent beauty exhibition of clay, the moist of water and the best use of hand and tools release clay's inherent plasticity; and the fire changes clay's microscopic aggregation through temperature and atmosphere, which makes the expending result for the hand and tools to the clay's inherent plasticity fixed as a law-like order. Because the earth gives body to bricks, so the brick with its own face to show poetic speech to earth. And because fire gives brick a long life, so also brick with its own face to show the fair speech. Fire speech is change and refining, high temperature forging is to remove the elements which unable to adapt to the harsh environment, the result is the change in the size, color and texture. As a result of purification and refining is to form a mullite inside the body, body hardening and densification, volume reduction, moisture removal and so on. The change beauty of fire presented as the fired body color and texture as well as the accidental beauty of the glaze after furnace transmutation. Such beauty has certain inner relationship with lava, weathered granite and other beauties formed by natural forces, they all reflect a natural beauty which detach from the instrumental rational creation motive. Clay color is dark gray and unpurified, after the fire change it present warm red and dark brown colors. Fair makes the beauty expression of early ceramic bricks and tiles is able to not reply on glaze. Brick and tile reflect the fire speech, and also fire allow them to talk freely, and the glaze mutation forms dripping, pure, gradual change, mottled and different language expressions. These color creations rely on natural forces will make the most skilled painters shame. From amorphous clay which attach to the earth to the hard and fixed building component, since the inner relationship between ceramic tile and earth, and the free speech offered by the fair, they make the final presentation of ceramic tile are still the original fragrance of the earth, loose of clay and dark red color of clay. The simple elegant beauty makes closer contact between man and nature to help people think about the original meaning of existence.

In addition to the above exhibitions of this simple and elegant beauty, architectural ceramics skin also has a luxury and sumptuous beauty with shiny glaze, the improvement of ceramic production technology makes the glaze emerged. Glaze protects the carcass, and also has appreciation function. Glaze appeared in ancient China first appeared in Shang Dynasty, through continuous improvement, glazed tile gives a new visual exhibit to clay art, glaze replaced the reproduction of ceramic tiles for the exposed earth, which formed people's gentle aesthetic of glassiness and jade-like quality. Earliest wood ash is the art of ash and fair, the carbonate and N.P.Ka, $\mathrm{Ca}, \mathrm{Mg}$ mineral components contained in the ash under the action of the fire melt into the glaze on brick surface, this kind of writing is the reproduction of order beauty creation, is the visual speech for the poetic effect. In China, glaze use of bricks in buildings could date back to the Northern Wei Dynasty, ancient architectures in China mainly use glass tile for surface decoration. Because use lead nitrate as a co-solvent, so that the toner better melt in lead glaze and appeared mottled flowing visual effects. Benefiting from the glaze material production experience of its adjacent areas of ceramics and glass containers, use a variety of colorants for coloring, the various oxides from nature exhibit different colors. After Song Dynasty glazes became the specified component for important 
national buildings. The beauty of glaze is the flowing shiny beauty.

Beautiful decoration is not piling up decorative elements, not carry out performance for performance. The decoration of architectural ceramics skin mainly with ceramic wall art, its decoration beauty reflects people's unique expression of poetry in different areas and different times. Hegel said: "Each work of art belongs to its age and its people, each with a specific environment, depends on specific history and other ideas and purposes." [11] The brick decorations of architectural ceramics skin in different eras all profoundly reflect the culture and national psychology of the times, and these cultural and historical factors also presented as a form of beauty through bricks and tiles. In contrast with Chinese and Middle East ancient architectural ceramics skin decorations: Islamic architecture influenced by taboo for biological image expressions in religious dogmas, and turn to artistic expressions of the plant patterns, dogmas text, water and other images. China's architectural ceramics wall decoration emphasis on artistic expressions of mural animal and mythological figures. From artistic expression, the ancient Islamic architectural ceramics decorations show the call for divinity and the human soul sublimation. Plant patters composition is limited by checks, which implied the constraint and remedy on human behavior. The wall full of floral ornamentation interlocking and extends upward to the top which implied divinity greeting and the greeting from human soul to sublimation. At the same time the endless plant also metaphor the soul is immortal and forever in vibrant world. Richness and order are the core of poetic expression and make integration of man and the world. Chinese architectural ceramics skin normally is dragon, phoenix, mythological figures, flowers and other plant patterns. Dragon patters are widespread on the front wall of the palace dragon wall art and pagoda on facades. High rilievo performance techniques and dense composition reflect the exquisite processing of space compression and the flow and circulation processing in a closed space. From the comparison of decorative performance practices, we can see: China's architectural ceramics decoration art normally use rilievo and high rilievo practices, Islamic and European architectural ceramics decoration prefer painting techniques; Chinese ancient architectural ceramics decoration art prefer the description of flowing sense and unfixed shape, (such like the dancing dancers in the Eastern Han bricks, goodness with waving band in Northern and Southern Dynasty, dragon curling on the sea in the dragon wall of Ming Dynasty) The Middle East architectural ceramics decorations which influenced by Islam in favor of symmetry fix and order constraints description (such like symmetrical plant patter performance based on realistic in 12-19 century Islamic mosques.)

Construction activity gives the abstract order beauty to architectural ceramics skin, and forms a kind of order beauty by paving layer by layer: tile's layer by layer arrangement and the sequentially paving of the bricks form a order beauty based on grid frame, tile is wavy extension, and brick is a square matrix divergence. The construction of architectural skin can be clarified with the modular thinking which pointed by Reid Hou: generation process of architectural skin can be considered as generation process of a standard component structure system of ceramic tile. Mass production of all kinds of bricks and tiles used in walls and roofs, reflected the modular production's advantages of low cost and long duration, but also show the beauty of standardized constitution. The order arrangement of bricks and tiles in architectural skin presented as the right-angle, dense and non-central ductibility, Gombrich in the book of "sense of order" quoted the view about expectation and unexpected things in information theory to explain aesthetic pleasure from some kind of objects between tedious and messy: "Monotonous pattern is difficult to attract people's attention, over complex pattern will cause the overload of our perceptual system and stop to watch, the reason why we will continue to use and enjoy hierarchical pattern is because this pattern is easy to re-create, and has a 'unity in diversity' feature. Paviors and other pattern makers always like to use this feature, there are many relatively simple shapes can be combined or overlapped in different ways, thereby formed a variety of new patterns. "[12] Ceramic brick wall surface are tightly attached by oblong or rectangular brick strips, their diversity and differences mainly exhibit through brick shape, size and color differences. The presentation of bricks' final appearance not only depends on potters' production, but also depends on the understanding of the masonry construction from masons and engineers. In the history, ceramic tiles once as an important wall bearing material (in history, wooden building wall structure is made of fence with coated clay and mud, and stone building wall structure is separately made with stone, brick, compacted soil block and stressed concrete), they are lighter than the stone and compacted soil but with the same pressure-resistant and solid, and in the corner place of some special shaped parts it shows the flexibility wit. For example, in the arc structure which Gaudi produced in 1878 in the Spanish region of Catalonia, brick changed the past arrangement order to extend with right angles and replaced with continually changing of the arrangement and angles, production technology[13]in handmade-Times makes the bricks difficult to ensure a consistent look, and the complex structure of the building made the body need to be cut when meet the corner structure, sometimes in order to fill the gap between the bricks the builders need to filled with cement, the Roman came up with a lot of masonry approaches in order to built arch structure, including filled the mortar between the bricks. They designed wedge-shaped bricks in the ceramics field of wall paving, Islamic temple appeared some complex and diverse geometric shapes: hexagonal tiles, triangular tiles and star shaped tiles. The same complex geometric order can also be found in Morocco handmade mosaic mural.

The order beauty of architectural ceramics skin is based on rigorous engineering and construction activities, the process of skin constructing is a systematic work, you need to find duplicated continuity in a single brick arrangement. People's first design to its structure is from the observation of animal scute which is a skin form that can effectively protect the structure. And observe the beauty of order and rhythm in this form. 


\section{The CUltural FunCtion OF ARCHITECTURAL CERAMICS SKIN - AS A RECORDER OF PLACE}

Norberg-Schulz called architecture a space for life occurred. In his "GENIUS LOCI", he said: "People want to settle down, then they must be able to identify the direction in the environment and agree with the environment. In short, he must be able to experience the environment which full of meaning. So settle down is not just 'shelter', in its true sense it refers to the space and place that life occurred. In ancient times, Genius loci has always been considered a specific fact that a person must face, and in everyday life he must also compromise with it. Architecture means the visualization of Genius loci." [14] In order to obtain identification with environment, we need to associate the architectural space with events happened when people in it. As Tschumi (Bernard Tschumi) in his "Space and Events" said: "As the sociality of architecture and the relevance of form creation, architecture cannot be separated from events which 'happened' in it".[15] Architectural Ceramics skin with a strong interpretation characteristics, through the material itself it can convey the appropriate architectural culture, which become the reproduction of different historical events, become the presentation of social order construction process in different historical stages, from which we can see the difference understandings of poetic living environment for people in different ages.

Architectural ceramics skin is the record and reproduction of people's lives in different times. A construction material contains a certain amount of cultural and emotional attribute, as a construction material for human to construct the history, brick as the architectural ceramics skin carries the expectations of ideal living environment for people in different times, it is the spiritual reproduction of living place in different times, it embodies the cultural factor of national collective inheritance. We tend to feel the heaviness of history change from those monuments and relics of skin construction: standing on the Great Wall remains we will be amazed by the amazing construction ability for ancients in relatively backward technology environment. It seems to appear the scene of two thousand years ago Emperor Qin Shi Huang in order to resist barbarian Huns use hundreds of thousands labor to build the north Great Wall by rock, grit and willow. Behind the motivations of material firing to the masonry repair is a complete human history, there is the desire to conquer, desperate and fearless to defend the homeland, agloat choice, people at different levels all contained in the birth of a military fortification, this is the genius loci contained in the construction objects. By the solidified objects to reflect the spirit condition at the times, the objects return to the narrative character of the construction age.

A construction material and its manifestation are related to the technology environment and cultural sites at that time, it is the material carrier of an era's spiritual culture. [16] From the color of architectural ceramics skin, different cultural context determines the corresponding color meaning. In western culture, blue symbolizes noble, lofty, deep; red because its visual association with blood and fire, it symbolizes life, love, passion, desire and war; green because its visual association with natural green plant growth, it symbolizes youth, hope , nature, healthy and so on; [17] In the Islamic culture which grow in the desert environment, green become sacred and noble color, they use blue green and such cool color ceramic tiles to decorate the spire and the dome of the mosque, which connect with the vegetation water inside and outside the building, not only with its cool psychological effects to become the oasis in the desert environment, but also symbolizes the heaven scene which integrate life paradise with blue sky. [18] In Chinese ancient Northern Wei Dynasty most facing bricks and eaves tiles all covered with black color, which related with people's black advocating culture in Northern Wei Dynasty.

As Heidegger said: "stand above the earth and among the earth, the diachronic human establish their dwellings among the world". The color use of architectural ceramics skin not only reflects the world cognitive plane in different nations, but also embodies human relations order in a certain historical stage. Material entity of architectural ceramics skin carries a variety of symbolism of architectural works, epitomized by the color use order and the image order. From the order of color use: Back in the Eastern Zhou period, "Chunqiu. Guliangzhuan" has detailed requirements of the color use of column, and the color specification about the wall decoration and roof glazed tile also very detailed. In history the red wall and yellow tile always specially used in royal buildings, important temples and imperial temples. The homes of ordinary people are prohibited to make decorations in the hall. The "Ming Shi" clearly documented the corresponding color system of the Princes, officers and ordinary people's mansions, "The main hall of Prince mansion use green glazed tile, decorative paintings could use bright red and green to gold pointing"; and officers' doors and windows are prohibit to use red painting, the walls brush decorated by loess, colored decoration is prohibited with ordinary people. The color use of roof tiles also reflects the distinct grade consciousness. "Roof Tiles: Prince can use green glazed tile, wing-room can use gray round tile, auxiliary buildings can use gray flat tile, the rest main houses all use gray round tile." From these strict regulations of decorative tile color use, we can see the construction activity is a presentation for pecking order. It embodies the order scene in social structure. [19] In history, the symbol of imperial power and the construction of pecking order are always achieved by the strictly limitation of certain symbolic color use and intense color saturation rendering. Such as the Royal Palace of the Qing Dynasty mostly use yellow glazed tiles, and prince mansions mostly use green glazed tile.

From the order appeared in the images, architectural Ceramics skin art often through the use order of dragon, phoenix totem symbols in order to emphasize the imperial status. The Tang Dynasty Hua Qing imperial ruins formerly known as "Yu Tang Jiulong Dian", "Long" character implied it is the emperor's bath and health resort, the dragon pattern eaves tile which been dig out highlight owner's noble status, due to dragon pattern eaves tile's symbolic meaning it resulted in the use range of their image and users are strictly limited. Another example is in the roof system of the ancient palace architectures, mythical animal always appeared as the order embodiment and the exhibitor of sky deity. Roof Art of ancient 
Chinese architecture has always been an important place for the production and dissemination of myth. Ancient building's roof with extremely tension help the building extend to the sky, and at the same time not only deepened the communication between sky and building, but also strengthen the communication between man and the sky. The ridge and beasts from the initial force support function change into the spiritual realm of myth production, they have become a kind symbol which borrow artistic poetry to express deity. Behind the mythical animal become moral, good luck and happiness, and ruling order, it implied the respect for the sky and some knowledge to the truth. It reflects the full measure of divinity in between heaven and earth, people from different classes try to get the ability to their advantages from deity, and place them overhead with great reverent attitude. Kylin does not step on any living creature, it is known as a symbol of virtue, therefore, emperors and dignitaries all like to build it in the palaces, temples and houses to show clear and good luck. Such like both ends of the roof ridge of ancient Chinese architectures, there normally are a beast with dragon head and turtle tail called "Chiwen" (also known as Long Wen). It is said that its eyes are extremely sensitive, so build it on the high ridge meaning it is able to perceive all kinds of weathers and ensure the permanent firmness of the architectures. The construction class of ancient Chinese architecture is proportionate to the number of animals, the biggest number for ridge animal is 11 , appeared on the ridge of Taihe Dian in Forbidden City which is the highest class. There carved 9 animals on the wing angle of Beijing Tiananmen Gate tower. The production motivation of them is pursue good fortune and avoid disaster, pray for peace and calm, and harmony weathers. [20] People use clay to produce mythical animals, during the production process not only give physical entities the totem images, but also make the sky and the earth assembled on the roof, in order to make the buildings has a mission to reveal the truth. Norberg-Schulz said: "We call the construction of a place as architecture. Through the architectures, people give meaning to the specific performance. At the same time concentrate buildings, figurative and symbolic forms of life as a whole. Therefore people's daily living world has become a very interesting house and enables them to live". People through the establishment of various symbols in architectural skin, transfer the strange and difficult to identity environment into "meaningful home".

\section{CONCLUSION}

Dwelling is the original purpose of people's construction activities, and poetic dwelling is the ultimate goal of construction activities, our expected dwellings not only provide a place to shelter from bad weather, but also create a "space for enjoyment life happen". In this space, people get a sense of belonging from it. Architectural history of mankind is a history of constant pursuit of poetic dwelling. Heidegger believed: Architectures from the meaning of building construction and tool manufacturing was only the result of dwelling nature, usually architecture just brought a wealth of merit into the dwelling. [21] Poetic dwelling will have to rely on poetic speech. Architecture through skin formation brick and tile to conduct poetic speech, which formed poetic architecture. Architectural ceramics skin is the faithful guardian of the building structure, the diligent weaver of building skin. In the walls and buildings which formed by it, it reflected the strict order like mathematics and stone-like firm which to some extent reject interference of dangerous unknown world, and against the invasion from alien civilizations and external nature. So it is a merit thing; also architectural ceramics skin is the poetic weaver, the roof layer upon layer achieved the communication between man and the sky, gave the sky a variety of imaginations which beyond substances. The brick wall which solid rooted in the earth achieved a fusion between man and the earth. Brick and tile are come from the earth, in their generation, standing and dying process they never left the earth, after they were abandoned they peacefully return to the earth. They became the divinity scale weavers in architecture works and conduct the poetic speech in the open world of architecture works. So they are the poetic things. At last, architectural ceramics skin represents the genius Loci, they continued the collective memory of the nation, from the level of human relations to conduct poetic interpretation. Through cultural symbols left in the brick and tile, they have seen dramatic events in the past era. So they are also human relations things.

While watching the moment, the three layers of the architectural ceramics skin function may be able to bring us more thoughts to our construction activities. From the human needs aspect, people today do not have to worry about looking for sheltered places and intimate spaces, our construction techniques could even show the glory which is like natural existence, surplus of technology makes the buildings try to break free of the earth and spy the sky. Brilliant technology is so bright, but did not eliminate our fears of desire and lose, capitalism makes money become the ultimate human needs, the capitalists taking advantage of people's demand of capital to constitute market demand, which constitute the motive power for capitalism to extended reproduction. Capitalism through price and advertising marketing, aggressively creates the demands. [22] The construction technology involved in the demands creation of consumer culture and with its luxuriant fashion mechanical copy type buildings to engulf the earth like necrotic cells. Devotion of the modern for craftsman suffered from material desire and merit, to make them not feel a sense of happiness.

Poetic dwelling need us to self-examine the things we have done and the things we are doing now, critically review and periodical self-examination could avoid us become a victim of technology fanaticism. The material vitality in architectural Ceramics skin is a poetic speech, the ceramic clay and porcelain mud that take from the earth contains the divinity filled in heaven and earth, during their life process of becoming the building elements, they have been given the spirit of different age's places. They are the signs of time events, time events through them to intact retained until now, whether the surging of the beauty of truth or the reproduction of historical scenes, all made them easy to touch our soft hearts and causing experience person's a sense of presence and sense of the times; they made us to think about the potential association with the regional mineral resources and geological structure. 
People are in the buildings covered by modern electronic machinery, still could use the simple and warm appearance of ceramic brick and tile to achieve the communication with earth and sky. Aesthetic of soil liberates us from instrumental reason and return to the kindness and pure poetic realm. In our time, poetic dwelling doomed to look back to self-examination human science and technology, but it cannot be a total negation of technology and art and escape into the eternal poetry of ancient Greek temples, it also cannot be the blindly praise to technology. From the brick and tile faces of architectural ceramics skin, we can see that the clay is honest and simple, it is the craftsmen's concentration and dedication. It is the economical construction which take from the earth and feedback to the earth. From brick and tile, we see our attachments to the nature, and passing glimpse of people's living conditions in the fading history. Consideration for poetry shall never stop.

\section{REFERENCES}

[1] [De] Heidegger "Poetic language thinking" [M] Peng Fuchun translation, Beijing: Culture and Art Publishing Company, 1991: 189.

[2] Same as [1]

[3] Xu Hengchun. Design aesthetics [M] Beijing: Tsinghua University Press, 2006: 49.

[4] Guo Honglei. Research on cognitive channels and construction methods of modern architecture skin $[\mathrm{J}]$. Jiangnan University doctoral dissertation, 2013, 49

[5] [JP] Yoshinaga. Wa (M), Shanghai: Shanghai Jiaotong University Press, 2015: 30 .

[6] Same as [5].

[7] Shen Yunyan. Research of Chinese Ancient Eave Tile [M] Beijing: Chinese Cultural Relics, 2006: 130.

[8] Li Yanzu. From Utilitarianism to Ethics - Realm and Philosophy of Design Art [J] literary study, 200510.

[9] [FR] Levi Strauss Jealous pottery female [M] Beijing: China Renmin University Press, 2006: 172-173.

[10] [DE] Hegel Aesthetics, Zhu Guangqian translation [M] Beijing: Commercial Press, 1979: 56

[11] [EG] E.H Gombrich Sense of order [M]. Hangzhou: Zhejiang Photography Publishing Company, 1987: 19.

[12] [US] Kenneth Frampton Construction Culture Research [M] Beijing: China Architectural Press, 2007: 7.

[13] [NW] Norberg-Schulz Genius Loci-Towards a phenomenology of Architecture $[\mathrm{M}]$. Wuhan: Huazhong University of Science and Technology Press, 2001: 34

[14] Feng Lu. Historical Perspective of the skin [J] Beijing: Architects, 2004 04.

[15] Chan Siyou. Study of the regional performance of architectural skin material $[\mathrm{J}]$ South China University of Technology doctoral dissertation, 2004: 28.

[16] Fu Xinian. Chinese history of science and technology - Architecture volume [M]. Beijing: Science Press, 2008: 699.

[17] Lo Gang, Wang Zhongshen. Consumer Culture textbook [M] Beijing: China Social Sciences Publishing Company, 2003: 96. 